\title{
Implications of Social Media Addiction on Academic Performance among Generation Z Student-athletes during COVID-19 Lockdown
}

\author{
Wan Ahmad Munsif Wan Pa, Muhammad Sofwan Mahmud* and \\ Mohd Syazwan Zainal \\ Universiti Kebangsaan Malaysia, Malaysia \\ https://orcid.org/0000-0001-6218-4376 \\ https://orcid.org/0000-0002-0504-4622 \\ https://orcid.org/0000-0002-1450-2760
}

\begin{abstract}
With the rapid advancement of internet technology, the increasing prevalence of smartphone ownership at a young age, the uncertainty surrounding the end of the COVID-19 pandemic, and the effect of social media addiction on academic performance among students, social media use will continue to be a major point of contention. However, student-athletes are a distinct group of students who should not be overlooked due to their concurrent commitments to studying, training, and competing. As such, this study sought to investigate the effect of social media addiction on academic performance among Generation Z student-athletes during Malaysia's COVID-19 lockdown. The research design used in this study was a quantitative cross-sectional survey. This study surveyed 91 respondents and utilized the Social Media Addiction Questionnaire (SMAQ) and Grade Point Average (GPA). The findings indicated that Facebook was the preferred social media platform over Instagram, Twitter, and YouTube, and that more than half of the participants were social media addicts. The researchers concluded that social media addiction had a significant impact on academic performance, accounting for 57.6 percent of the variance. These findings imply that excessive social media use, leading to addiction, has a significant negative effect on academic performance. Solutions are desperately needed, such as turning off notifications, silencing the phone, engaging in home workouts, reconnecting with family, or taking up new hobbies.
\end{abstract}

Keywords: social media addiction; academic performance; studentathletes

*Corresponding author: Muhammad Sofwan Mahmud; sofwanmahmud@ukm.edu.my 


\section{Introduction}

Coronavirus 2019 (COVID-19) was discovered for the first time in December 2019 in Wuhan, Hubei Province, China, causing the World Health Organization (WHO) to declare it a global pandemic which poses a physical and psychological threat to the public. The continued spread of COVID-19 is a public health emergency and a global hazard. To prevent the disease from spreading further, governments have issued emergency orders for people to stay at home, while universities and schools have been closed. It has been estimated that, by March 26, 2020, the closures affected more than 150 million children and adolescents in 165 nations (UNESCO, 2020). Due to the COVID-19 pandemic, higher education institutions have been forced to implement emergency online learning (Yahya, Rahman \& Siddiq, 2021). On top of that, this pandemic has become a source of stress since it has had an impact on all sectors of human existence, including economy, social activities, health, education, politics, culture, and communication.

Based on statistics provided by the Ministry of Health (2021), Selangor was one of the states in Malaysia with the highest number of daily positive COVID-19 cases during the movement control order 2.0 (MCO). During this pandemic lockdown, communication has encompassed much more than just sending messages to people. Communication is the process of conveying or exchanging information through speech, writing, or any other medium (Buck, 2019). Additionally, information and communication technologies (ICTs) are now widely used in virtually every aspect of human life, including entertainment, education, decision-making, information searching, commerce, and business. In terms of benefits, ICTs can help people to save time, effort, and money (Filimon et al., 2017).

The importance of communication through social media is obviously seen as a funnel for information between family members, education, entertainment, and other activities, as well as a vehicle for a child's socialization and education from birth to adulthood. Social media platforms are one of the most widely used forms of information on the planet. Social media platforms include Facebook, Instagram, Twitter, Snapchat, YouTube, blogging platforms, Newsfeeds, Wikis, and social gaming platforms (Kuss et al., 2014). On the other hand, excessive use of social media has developed into a problem for some individuals who exhibit signs of behavioral addiction such as salience, mood modulation, withdrawal, tolerance, and conflict (Hawi \& Samaha, 2019).

However, a study on social media addiction among Generation Z studentathletes was limited by the fact that previous research focused exclusively on sedentary Generation Z students (Curtis et al., 2019; Gazi \& Çetin, 2017; Grau, Kleiser \& Bright, 2019). The requirements of a student-athlete's academic course must be balanced with their athletic activity. Ryba et al. (2015) asserted that the economic, structural, and institutional rules in place create a one-of-a-kind structure that enables a student-athlete to pursue a successful dual profession. These Generation $\mathrm{Z}$ student-athletes are not immune to the internet's rapid growth, technological advancements, and social media proliferation. 


\section{Problem Statement}

When COVID-19 isolates households from one another, parents and guardians may become concerned about their own financial future, making learning at home more difficult, particularly for children who lack motivation (Daniel, 2020). Students' lives have been significantly impacted by the COVID-19 pandemic in a variety of ways, depending on their level and field of study, as well as their program of study. Additionally, several students have found themselves unable to complete their university curriculum and assessments in a timely manner, and in many cases, they have been immediately cut off from their social group. Social media is critical as a communication tool for conveying information in these circumstances. Individuals frequently turn to the media in response to everyday annoyances and adversity. According to Zhao and Zhou (2021), when confronted with COVID-19 problems, such as venting emotions for mood management or joining online communities for social support, people tended to turn to social media for problem-focused activities, such as searching for health-related information and emotion-focused coping.

Despite the obvious benefits of social media in an emergency, such as COVID19, increased social media use is likely to result in social media addiction (Zhao \& Zhou, 2021). Social media's positive and negative effects on society are well established (Bajpai, 2018). On the other hand, they promote a sense of belonging and an excellent marketing or communication tool for businesses, political parties, and governments. Interacting with others on social media aids in the development of communication and technical abilities. Meanwhile, concerns have been raised about possible links between frequent social media use and anxiety and depression (Pa et al., 2020), as well as issues surrounding cyberbullying, online harassment, and "trolling."

According to Hootsuite and We Are Social's digital usage studies, Malaysia has the fifth-highest mobile social media penetration rate in the world and the highest in Southeast Asia (Bernama, 2019). According to the same survey, internet penetration has reached $81 \%$ in Malaysia, with users spending an average of eight hours and five minutes online. During the same time period, individuals spent two hours and 59 minutes on social media platforms like Facebook, Instagram, and Twitter. On the other hand, many individuals take advantage of these opportunities by devoting significant time to social media (Schulze, Scholer \& Skiera, 2015). Numerous studies have established a link between social media use and academic achievement and performance among international undergraduate university students. According to a nationwide survey of 3000 college students, $90 \%$ of students use Facebook and $37 \%$ use Twitter (Dahlstrom et al., 2011). As a result of the long hours they spend on social media, students are more susceptible to addiction, which can result in assignment procrastination, loss of focus, and can have a negative impact on their academic performance.

Moreover, student-athletes are among those affected by the lockdown pandemic. They had to cancel training and tournament for an uncertain period of time. Furthermore, they have a lot of free time and can easily become addicted 
social media users. This situation is supported by statistics reported by Kashif and Aziz-Ur-Rehman (2020) in which most people are becoming addicted to social media because of the spare time they have gained due to the suspension of all outside activities; many also reported feeling agitated and nervous if they did not use social media during the coronavirus lockdown. People have been spending more time on social media, which causes them to be distracted and delayed in their work.

Additionally, there is evidence of the devastating effect of social media on academic success, particularly Facebook, and smartphone use (Paul, Baker, \& Cochran, 2012; Junco \& Cotton, 2012; Samaha \& Hawi, 2016; Lepp, Barkley, \& Karpinski, 2015; Samaha \& Karpinski, 2016). When these tools are combined, students spend more time interacting with them than they do learning. Recent studies indicate that students' excessive use of social media can have a detrimental effect on their academic performance (Skiera, Hinz, \& Martin-Span, 2015; Al-Menayes, 2014; Skiera, Hinz, \& Martin-Span, 2015). Due to their pervasiveness, students are more susceptible to social media and smartphones than the general population (Giunchiglia et al., 2018). On the other hand, student-athletes are a category of students that should not be ignored because they are committed to three main goals at the same time, which are studying, training, and competing.

As a result of the difficulties, the researchers gained a better understanding of the negative impact of social media addiction on academic performance. Additionally, this type of study on Malaysian Generation Z student-athletes was uncommon, as previous studies focused on the general university student population. The most frequently used social media platform by Generation $Z$ student-athletes in Malaysia is unknown. It is critical to understand the mediators of the relationship between social media addiction and academic performance in order to identify risk factors and develop social media addiction prevention strategies. Indeed, these issues inspired the researchers to conduct a study on the impact of social media addiction on academic performance. Therefore, the present research aims to:

1. To recognize the most frequently used social media platforms by Generation Z student-athletes during MCO 2.0.

2. To identify the extent to which Generation $Z$ student-athletes are addicted to social media.

3. To determine the impact of social media addiction on academic performance in Generation Z student-athletes.

The research questions:

i. What is the most common type of social media platform used by Generation Z student-athletes during MCO 2.0?

ii. What is the level of social media addiction among Generation $Z$ studentathletes?

iii. What is the effect of social media addiction on academic performance among Generation Z student-athletes? 
The null hypothesis:

Ho: There is no significant impact of social media addiction on academic performance among Generation Z student-athletes.

\section{Literature Review}

During the COVID-19 pandemic, excessive levels of stress and addiction to social media are positively related (Brailovskaia et al., 2019). At the same time, people are helpless because they need to maintain their social media activity and communicate with their loved ones through social media (Perrin, 2015). Indeed, many people have been spending an increasing amount of time on social media platforms like Facebook and Twitter, in addition to remote work and study, which may satisfy their needs for disaster-related information, entertainment, and interpersonal communication (Merchant \& Lurie, 2020). Zhao and Zhou (2021) reported that when individuals are exposed to COVID-19-related stress, they are more likely to actively engage with social media, such as sharing personal feelings in order to alleviate unpleasant emotions.

According to statistics, the total number of users on social media has been increasing by 10 percent on a yearly basis, (Hawi \& Samaha, 2017). Numerous researchers and academics are examining the effects of social media technologies and applications on various aspects of people's lives, as they have become an inseparable part of daily life in recent years (Filimon et al., 2017). With the increasing use of smartphone technology, social media usage among adults aged 18 to 29 years in the United States of America has surged from 12 percent to 90 percent since 2005 (Sutherland et al., 2018). Due to the ease and low cost of Internet access and the enormous number of registered users on social media, these platforms are one of the simplest and most effective methods of spreading and obtaining information. Whether it is a sporting event, disease, or natural disaster, the overall response to important events is usually to search for information (González-Padilla, 2020). According to a recent study, users use social media for a variety of reasons, including seeking knowledge, seeking social engagement, avoiding boredom and leisure, fleeing unpleasant emotions, and seeking happy ones (Brailovskaia, Schillack \& Margraf, 2020). Thus, social media has a great impact on how people connect, work, and share information.

Social media networking via smartphone has also become the fastest growing method of affiliation due to its ability to quickly transmit essential information. Although social media has had an impact on a variety of businesses, it has had the most significant impact on classroom teaching and the educational system as a whole (Sivakumar, 2020). Some institutions use social media to promote programs and engage with current and potential students, as well as alumni, due to the popularity of social media. Some academics have embraced social media to improve the educational process and cooperate on projects, as well as to improve learning outcomes by communicating with students more effectively. According to the literature, undergraduate students at bachelor level are the ones who use social media platforms to engage with other students and university professors (Duggan et al., 2015; Head, 2013; Kim, Sin \& Tsai, 2014). 
Students' use of social media applications has exploded in the last decade, and the impact on academic performance has been mixed (Alnjadat et al., 2019). A survey of 30 male students at the Petroleum Institute in Abu Dhabi, in the United Arab Emirates (UAE), discovered that students with a high Grade Point Average (GPA) spend a significant amount of time on social media websites and applications (Tayseer et al., 2014). According to Alahmar (2017) and Boateng and Amankwaa (2016), social media was used positively in the learning process in China and Iraq, with students using the platform to discuss assignments and other coursework; receive news and updates on class schedules and locations; exchange information with peers; and express concerns about their academic work. Similarly, research conducted in Australia in 2018 reported that 67 percent of 106 undergraduate students polled cited technology as a factor in their successful academic achievement (Sutherland et al., 2018). Thus, social media has become ingrained in the lives of Internet users, and the increasing pervasiveness of smartphones is just accelerating this trend (Giunchiglia et al., 2018).

According to Al-Menayes (2014), while strolling, traveling by bus or train, or even driving a car, smartphones can be used as instructional and communication devices. A decade ago, micro time intervals during which users could engage in a variety of online activities were not possible. Micro time slots, on the other hand, can result in compulsive smartphone use, which prevents face-to-face interaction and has a detrimental effect on academic performance. Students who spent an excessive amount of time interacting on social networking sites were more likely to fail their classes (Alnjadat et al., 2019). Additionally, students who were heavily involved in social networking site activities while studying lacked focus and were easily distracted (Okyeadie Mensah \& Nizam, 2016).

On top of that, Generation $\mathrm{Z}$ is the generation that has grown up with a lot of technology, gadgets, and access to the Internet. According to Glass (2007) in Salleh, Mahbob and Baharudin (2017), a generation is defined as the length of time that individuals live in a certain year or a cohort of that year. Generation Z is the most recent generation to be born, and will rule the planet for the next decades (Wiedmer, 2015; Salleh, Mahbob \& Baharudin 2017). Singh (2014), Jaleniauskiene and Juceviciene (2015) and Schroer (2016) defined Generation Z as those born between 1995 and 2012. This generation appears to have been genetically modified by the Internet since birth. This is because they were born after the Internet became widely used around the world. Table 1 shows the dominant characteristics of each generation in the $20^{\text {th }}$ and $21^{\text {st }}$ centuries (MacKenzie \& McGuire, 2016; Glass, 2007; Wiedmer, 2015):

Table 1: Generation dominant characteristic

\begin{tabular}{|c|c|c|}
\hline Generation & $\begin{array}{c}\text { Range of birth } \\
\text { years }\end{array}$ & $\begin{array}{c}\text { Dominant behavioral } \\
\text { characteristics }\end{array}$ \\
\hline Traditionalist & $1927-1945$ & Disciplined and loyal \\
\hline Baby Boomers & $1946-1964$ & $\begin{array}{c}\text { Work ethics that are responsible } \\
\text { and strong }\end{array}$ \\
\hline Generation X & $1965-1980$ & $\begin{array}{c}\text { Thinkers who are autonomous and } \\
\text { productive }\end{array}$ \\
\hline
\end{tabular}




\begin{tabular}{|c|c|c|}
\hline Generation Y & $1981-1994$ & $\begin{array}{c}\text { More self-assured in social } \\
\text { situations, but less self-sufficient }\end{array}$ \\
\hline Generation Z & $1995-2012$ & $\begin{array}{c}\text { Inadequate communication skills, } \\
\text { excessive reliance on technology }\end{array}$ \\
\hline
\end{tabular}

According to Salleh, Mahbob and Baharudin (2017), most of the characteristics described have yet to manifest because this generation were born during technological explosions. Table 2 illustrates the four specific characteristics of Generation Z:

Table 2: Characteristics of Generation Z

\begin{tabular}{|c|c|}
\hline Characteristics & Description \\
\hline $\begin{array}{c}\text { Instant } \\
\text { gratification }\end{array}$ & $\begin{array}{c}\text { Generation } Z \text { has become impatient, requiring } \\
\text { immediate gratification, introverted, and } \\
\text { disconnected from society because of extensive } \\
\text { internet exposure. }\end{array}$ \\
\hline $\begin{array}{c}\text { Hypertext } \\
\text { mindset }\end{array}$ & $\begin{array}{c}\text { Generation Z prefers to watch videos over reading } \\
\text { hardcopy materials, such as books and manuals. }\end{array}$ \\
\hline Overprotected & $\begin{array}{c}\text { Spoon-feeding by parents is a common occurrence } \\
\text { in Generation Z. They are likely to demand that } \\
\text { institutions create a similar environment in this } \\
\text { scenario. }\end{array}$ \\
\hline $\begin{array}{c}\text { Ineffective } \\
\text { communication } \\
\text { abilities }\end{array}$ & $\begin{array}{c}\text { Generation } Z \text { is described as being more } \\
\text { individualistic, self-absorbed, and team-oriented } \\
\text { than previous generations on a limited basis. }\end{array}$ \\
\hline
\end{tabular}

\section{Theoretical Framework and Conceptual Framework}

Active use of social media could contribute to the effects of COVID-19-related stress on the relationship between social media addiction and academic performance. Active use refers to activities that enable direct communication with others, such as commenting on friends' posts, tagging, "liking," updating one's status or sharing images or videos. By contrast, passive use refers to the act of browsing news feeds or viewing other people's posts without engaging in direct communication (Burke, Kraut \& Marlow, 2011). A student-athlete, according to Pato et al. (2014), is a full-time university or high school student who participates in athletics or sports independently or as a member of a federation, club, or sports organization. Therefore, student-athletes need to divide their time between training, competition, and studies as well. In this study, the researchers adopt Social Learning Theory (SLT) as a fundamental knowledge to understand the addiction to social media among Generation Z student-athletes. According to the SLT, children and adolescents learn through observing their surroundings, especially those who are close to them (Bandura, 1977). People are devising new strategies and techniques to inform, prepare, and teach others, which is a human phenomenon known as planned socialization. Both natural and deliberate socializing, according to Ransome and Sampford (2016), are beneficial to living a purposeful life. Figure 1 illustrates the theoretical framework that consists of three components under SLT, adapted from Bandura (1977) in Ghazali and Ghani (2018), while Figure 2 illustrates the conceptual framework that consists of four sections. 


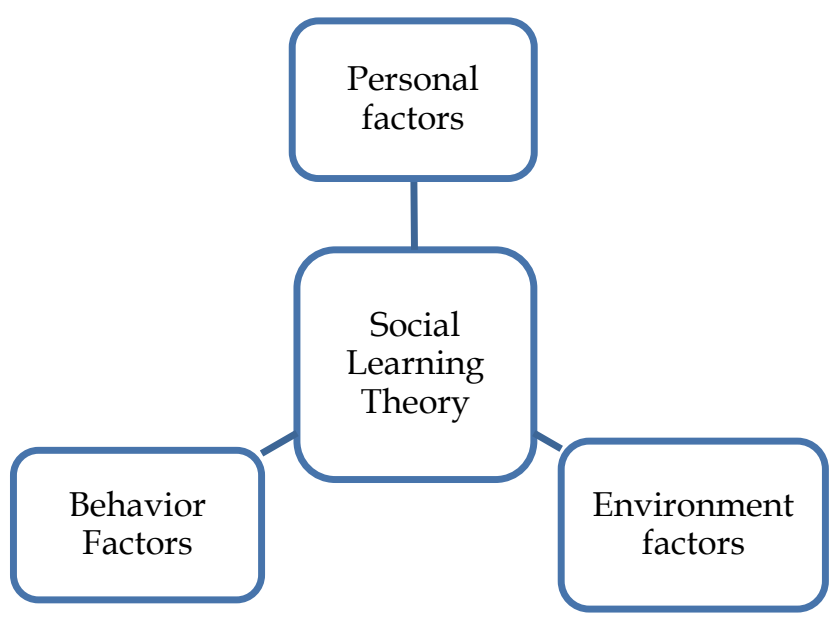

Figure 1: Interconnectedness of behavioral, environmental, and personal aspects that drive Generation $\mathrm{Z}$ behavior.

- Personal factors: huge amount of free time during pandemic lock down, stress, previous media exposure, business interest.

- Environment factors: social reinforcement, availability, group norms, peer pressure.

- Behavioral factors: Social media platforms enable students to share, create, exchange, discuss, and obtain information and ideas online in networks and virtual communities. However, if the students cannot control the amount of time using the social media, this situation can potentially lead to social media addiction behaviors.

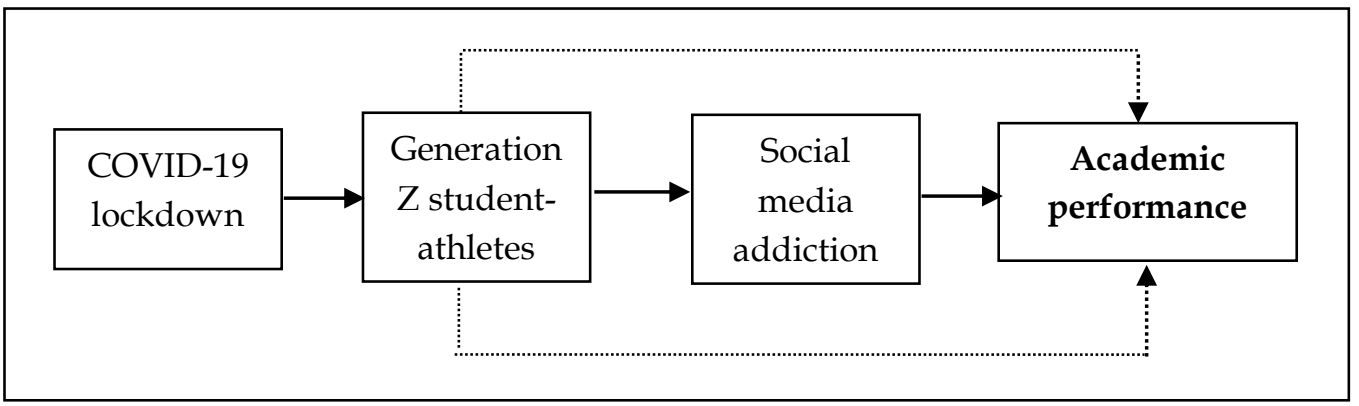

Figure 2: The conceptual framework for the research

The conceptual framework is a generative framework that encapsulates the research process in its essence (Adom, Hussain \& Joe 2018). The conceptual framework depicted in Figure 2 was created for each of the study's processes and the underlying variables used to review the new search results. The study concept is derived from the researchers' reading of the literature.

\section{Research Type, Sample, and Study Context}

The researchers used a cross-sectional survey design in this study, combined with quantitative methods. The sampling technique in this study was a probability sampling, specifically cluster (area) random sampling. This is 
because the respondents were located within a 10-kilometer radius, studentathletes born between 1995 to 2012 and the data collection was performed after the first phase of COVID-19 MCO 2.0 in Malaysia (19th February 2021 until $^{\text {rd }}$ March 2021). This technique was ideal for us as researchers as we had limited finances, time, and energy resources; while also being concerned about staying safe from the threat of COVID-19 infection, and our accessibility to respondents, specifically Generation Z student-athletes who resided on the campus of Universiti Kebangsaan Malaysia. The University is a public institution of higher education in Bangi, Selangor. The institutional research board of the University granted permission for the investigation. Before volunteers began the survey, they were given a consent form explaining the study's objective and assuring them that the data collection, storage, and reporting processes would ensure confidentiality and anonymity. The Statistical Package for the Social Sciences (SPSS) version 25 was used for data entry and analysis. A simple descriptive analysis was conducted in the form of numbers and percentages. To discover the contribution between variables, simple linear regression was implemented as a test of significance, with a threshold of less than 0.05 considered significant.

\section{Data Collection Instrument}

The survey was divided into three sections, one for demographic data collection and the other two for independent research instruments. Gender and social media type were provided in the demographic information section. The remaining sections were composed of the Social Media Addiction Questionnaire (SMAQ), adapted from Hawi and Samaha (2017) and Grade Point Average (GPA) academic performance. The highest GPA awarded is an A, which is worth ten points, and the lowest is an E, which is worth zero points. Meanwhile, The Social Media Addiction Questionnaire (SMAQ) is an eight-item questionnaire designed to assess social media addiction. Responses were recorded on a seven-point Likert scale ranging from 1 (strongly disagree) to 7 (strongly agree), with higher scores indicating greater levels of addiction. Table 3 shows the seven-point Likert-type scale; Table 4 shows the three sections of the research instrument; Table 5 shows the norms for SMAQ; and Table 6 shows the breakdown of (GPA) academic performance.

Table 3: 7-point Likert-type scale

\begin{tabular}{|c|c|c|c|c|c|c|}
\hline $\begin{array}{c}\text { Strongly } \\
\text { disagree }\end{array}$ & Disagree & $\begin{array}{c}\text { Somewhat } \\
\text { disagree }\end{array}$ & Neutral & $\begin{array}{c}\text { Somewhat } \\
\text { agree }\end{array}$ & Agree & $\begin{array}{c}\text { Strongly } \\
\text { agree }\end{array}$ \\
\hline 1 & 2 & 3 & 4 & 5 & 6 & 7 \\
\hline
\end{tabular}

Table 4: Three section of Research Instrument

\begin{tabular}{|l|l|l|l|}
\hline \multicolumn{2}{|l|}{ Section } & Item & $\begin{array}{l}\text { Category } \\
\text { of data }\end{array}$ \\
\hline $\begin{array}{l}\text { Section } \\
\text { A }\end{array}$ & Demographic & Gender & Nominal \\
\cline { 3 - 3 } $\begin{array}{l}\text { Section } \\
\text { B }\end{array}$ & $\begin{array}{l}\text { Social media } \\
\text { addiction }\end{array}$ & $\begin{array}{l}\text { I frequently consider social } \\
\text { media when I am not actively } \\
\text { using it. }\end{array}$ & $\begin{array}{l}\text { Ordinal } \\
\text { (Likert } \\
\text { scale) }\end{array}$ \\
\cline { 3 - 3 } & $\begin{array}{l}\text { I frequently use social media } \\
\text { for no discernible reason. }\end{array}$ & \\
\hline
\end{tabular}




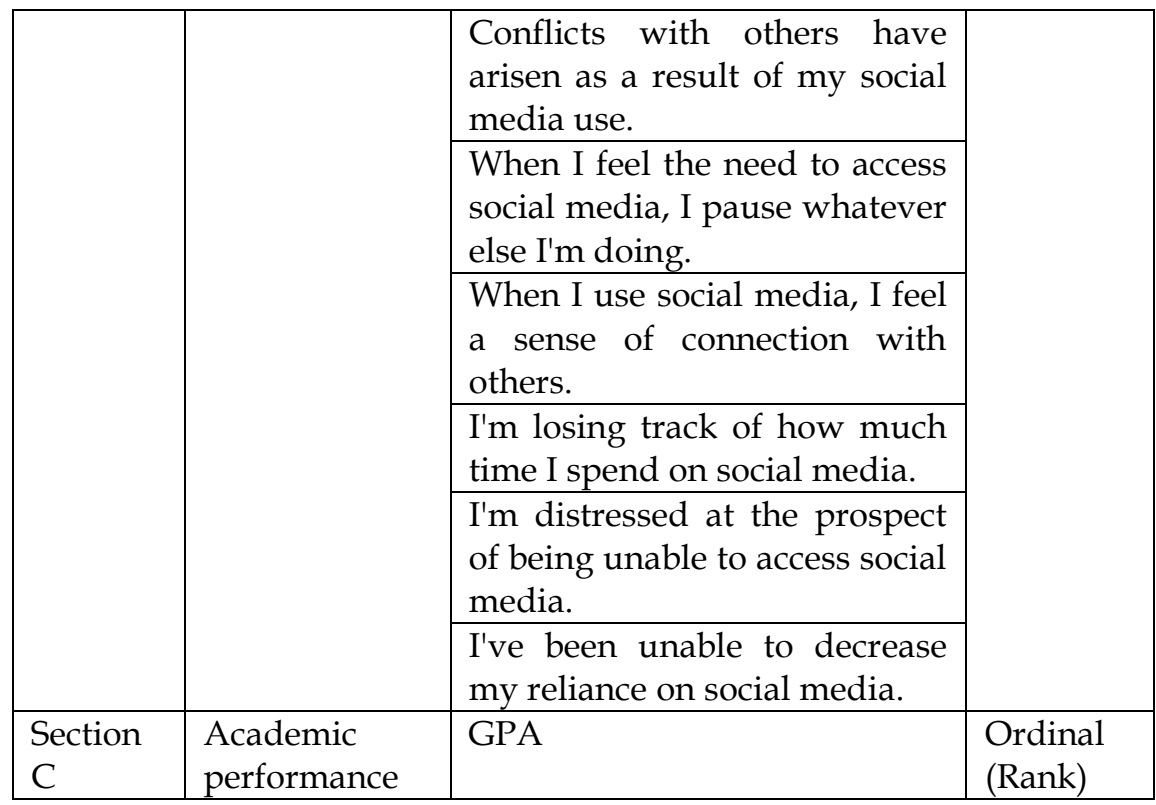

Table 5: Norms for SMAQ

\begin{tabular}{|c|c|}
\hline Level of social media addiction & Score \\
\hline Low & $<7$ \\
\hline Moderate & $8-50$ \\
\hline High & $>51$ \\
\hline
\end{tabular}

Table 6: Breakdown of (GPA) academic performance

\begin{tabular}{|c|c|c|}
\hline Grade & Value & Rank \\
\hline A & 4.00 & 10 \\
\hline A- & 3.67 & 9 \\
\hline B+ & 3.33 & 8 \\
\hline B & 3.00 & 7 \\
\hline B- + & 6 \\
\hline + & 2.67 & 5 \\
\hline C- & 2.33 & 4 \\
\hline D+ & 2.00 & 3 \\
\hline D & 1.67 & 2 \\
\hline E & 1.33 & 1 \\
\hline
\end{tabular}

Due to lockdown and the $10 \mathrm{~km}$ radius of travel restrictions imposed by the Malaysian government to break the COVID-19 chain, the instrument was distributed by using email and the respondent required to answer and return to the researchers through email as well. Previously, a pilot test had been conducted with 76 Generation $Z$ student-athletes from several public universities in Malaysia. The reliability was tested using SPSS version 25, and yielded a Cronbach alpha value between 0.67 - 0.89. According to Chua (2014), Cronbach's alpha coefficient should be between 0.65 to 0.95 which is high and satisfactory. Meanwhile, preliminary analyses of all simple linear regression analyses were conducted to ensure that the normality, linearity, multicollinearity, and homoscedasticity assumptions were not violated. 


\section{Findings}

The study questionnaire was completed by 91 Generation $\mathrm{Z}$ student-athletes out of a total of 120 invitees (a response rate of $76 \%$ ); specifically, 57 (62.6\%) were male student-athletes and 34 (37.4\%) female student-athletes. The range of birth year was 1995-1998 (36.3\%) and 1999-2002 (63.7\%). Descriptive analysis was performed to answer the first and second research questions. Figure 3 showed type of social media frequently used by respondents.

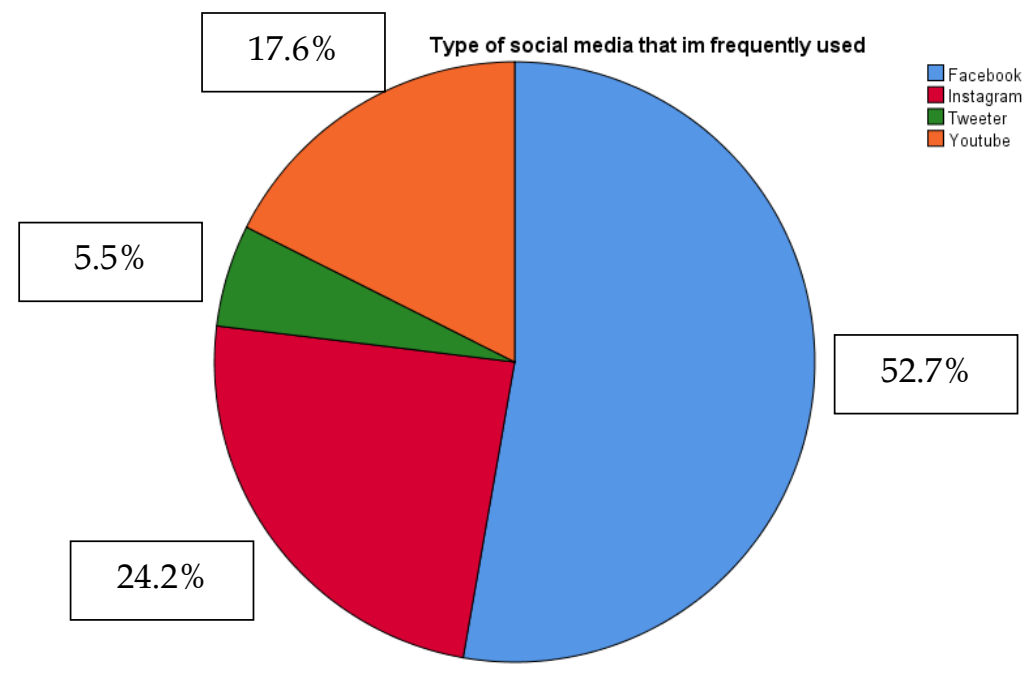

Figure 3: Type of social media frequently used by respondents during MCO 2.0.

Based on Figure 3 above, $52.7 \%$ of Generation Z student-athletes preferred to use Facebook; $24.2 \%$ preferred Instagram; 5.5\% preferred to use Twitter; and $17.6 \%$ preferred YouTube. Figure 4 showed the level of social media addiction among Generation Z student-athletes.

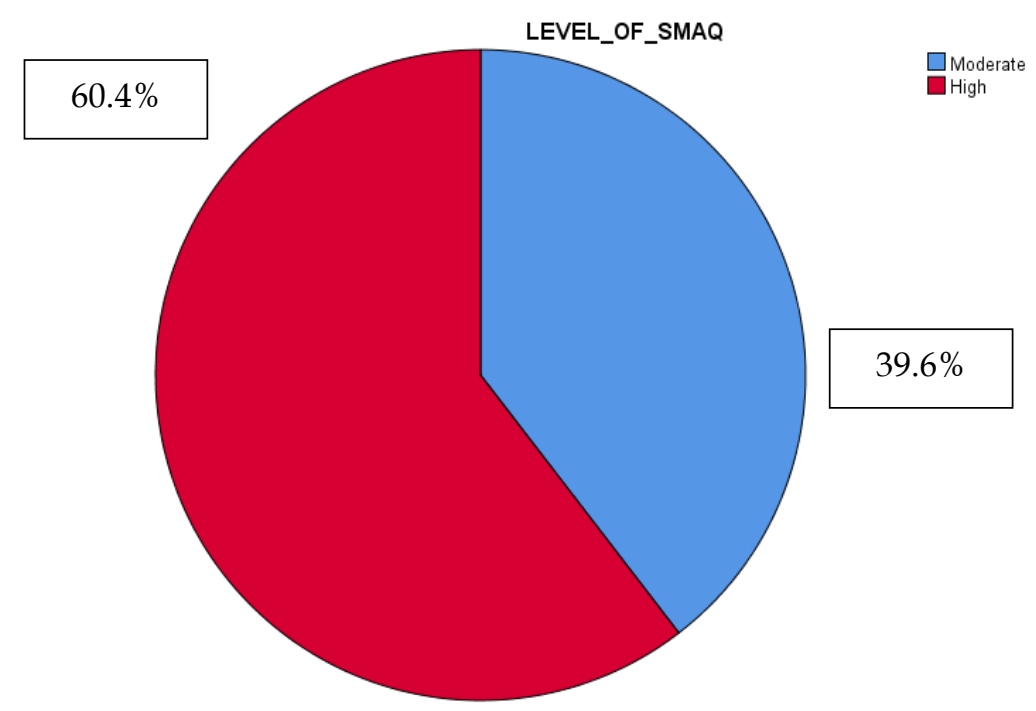

Figure 4: Level of social media addiction among Generation Z student-athletes. 
Based on Figure 4, results showed that $39.6 \%$ of Generation Z student-athletes were moderately addicted to social media. However, $60.4 \%$ of Generation $Z$ student-athletes were highly addicted to social media.

Table 6: Simple linear regression test of the impact of social media addiction on academic performance

\begin{tabular}{lllllll}
\hline \multicolumn{2}{l}{ Model } & $\begin{array}{l}\text { Sum of } \\
\text { Squares }\end{array}$ & df & $\begin{array}{l}\text { Mean } \\
\text { Square }\end{array}$ & F & Sig. \\
\hline 1 & Regression & .014 & 1 & .014 & .032 & .048 \\
& Residual & 39.283 & 89 & .441 & & \\
& Total & 39.297 & 90 & & & \\
\hline
\end{tabular}

As shown in Table 6, the Simple Linear Regression yielded a significant value of $\mathrm{p}=0.048(\mathrm{P}<0.05)$. In conclusion, these findings indicate that the null hypothesis (Ho1) was rejected, social media addiction had significantly contributed to academic performance. Therefore, the researchers referred to the test of Coefficients and $R^{2}$ value to determine the extent to which social media use affects the academic performance of Generation $\mathrm{Z}$ student-athletes.

Table 7: Coefficients Test

\begin{tabular}{|c|c|c|c|c|c|c|c|c|c|}
\hline \multirow{2}{*}{\multicolumn{2}{|c|}{ Model }} & \multicolumn{2}{|c|}{$\begin{array}{l}\text { Unstandardized } \\
\text { Coefficients }\end{array}$} & \multirow{2}{*}{$\begin{array}{l}\text { Standardized } \\
\text { Coefficients } \\
\text { Beta }\end{array}$} & \multirow[b]{2}{*}{ Sig } & \multirow[b]{2}{*}{$\mathbf{R}$} & \multirow{2}{*}{$R^{2}$} & \multirow{2}{*}{\multicolumn{2}{|c|}{$\begin{array}{c}\text { Percentage } \\
(\%)\end{array}$}} \\
\hline & & B $\quad$ E & & & & & & & \\
\hline \multirow[t]{2}{*}{1} & (predictor) & 6.068 & 1.712 & & 3.544 & .001 & & & \\
\hline & $\begin{array}{l}\text { Social } \\
\text { media } \\
\text { addiction }\end{array}$ & 0.48 & 0.270 & .019 & .179 & .0048 & 0.019 & 0.576 & $57.6 \%$ \\
\hline
\end{tabular}

Predictor: social media addiction

Dependent variable: GPA

As presented in Table 7, the Coefficients test showed that the correlation between the dependent variable and the predictor variable was $R=0.019$. Linear Regression Analysis was found to be significant $[\mathrm{F}(1,89)=0.032, \mathrm{p}=0.048$ (P $<0.05)$ ] and $\mathrm{R}^{2}$ equivalent to 0.576 showed that $57.6 \%$ of the change in the dependent variable of academic performance was due to social media addiction. Thus, the researchers concluded that social media addiction significantly impacted academic performance by $57.6 \%$. This can result in procrastination about assignments, loss of attention, and can have a negative impact on their academic achievement. Okyeadie Mensah and Nizam (2016) stated that, students who were immersed in social networking site activities while studying lacked focus and were easily distracted. These findings suggest that social media addiction has a significant negative effect on academic performance, and that solutions, such as turning off notifications, silencing the phone, engaging in home workouts, reconnecting with family, or discovering new hobbies are urgently needed to overcome it. Interventions that can assist Generation Z student-athletes regulate and lessen their social media addiction are also critically needed. 


\section{Discussion}

The COVID-19 pandemic has posed a serious threat to educational systems. This perspective offers guidance to academics, administrators, and government officials on how to address the crisis. With the rapid advancement of internet technology, the widespread use of smartphones at a young age, and the uncertainty surrounding the end of the COVID-19 pandemic, social media addiction will continue to be a topic of discussion in relation to students' academic performance. It is undeniable that social media has a huge impact on students from a variety of perspectives, as it has become ingrained in their lives, particularly social media platforms, such as Facebook, Instagram, Twitter, Snapchat, and YouTube, as well as blogging sites, newsfeeds, wikis, and social gaming platforms. Students benefit from their ease of use and accessibility because it saves them time and energy. For instance, students can now access Facebook or Instagram from anywhere and at any time via a smartphone. This social media phenomenon has resulted in a massive information flow in developed countries and Malaysia, ranging from remote areas to the middle of cities and regardless of age or race. As a result, most university students can gain access to a greater variety of information more easily and quickly.

This study investigated the effects of social media on Generation Z studentathletes. The major goal of this study was to see if there was a correlation between social media usage and academic performance. Our findings revealed that more than $50 \%$ of Generation $\mathrm{Z}$ student-athletes preferred to use Facebook as their main social media platform compared to Instagram, Twitter and YouTube. Next, our findings showed that $60.4 \%$ of Generation Z studentathletes were highly addicted to social media during MCO 2.0 in Malaysia. This could be attributed to a huge amount of free time and stay at home restrictions imposed by the government. These findings were also in line with previous research by Kashif and Aziz-Ur-Rehman (2020), that stated most people are becoming addicted to social media because of the extra free time they now have due to the suspension of all outside activities, and many individuals are becoming agitated and frightened if they do not use it during the coronavirus lockdown. Moreover, our findings revealed that social media addiction significantly contribute $57.6 \%$ to the respondents' academic performance. Future researchers can also expand the number of respondents and conduct interviews using a variety of methods, such as a mix of quantitative and qualitative techniques. It is also worth mentioning that the research found no gender differences. Furthermore, results must be replicated for specific demographics, such as gender and age differences.

In conclusion, no one can be left behind with their social media addiction. We do not want Generation $\mathrm{Z}$ student-athletes to be unproductive citizens who interact infrequently with other humans and rely heavily on technology, which will inevitably result in a variety of symptoms in the future. In Malaysia, Generation $\mathrm{Z}$ student-athletes must be media literate users in order to comprehend and utilize social media to a degree. However, it is necessary to revert to a more normal state of life in which one understands how to divide time between oneself, the surrounding community, and spiritual needs. 


\section{Acknowledgements}

This study was fully funded by FPEND Research Grant: GG-2019-003, Pemerkasaan Penerbitan Ahli Pusat Pendidikan dan Kesejahteraan Komuniti, Faculty of Education, Universiti Kebangsaan Malaysia.

\section{References}

Adom, D., Hussain, E. K., \& Joe, A. A. (2018). Theoretical And Conceptual Framework: Mandatory Ingredients Theoretical And Conceptual Framework: Mandatory Ingredients Engineering. International Journal of Scientific Research, 7(1), 93-98.

Al-Menayes, J. (2014). The relationship between mobile social media use and academic performance in university students. New Media and Mass Communication, 25, 2329.

Alahmar, A. T. (2017). The influence of social networks on the grades of medical students at University of Babylon, Iraq. July. https:// doi.org/10.5455/jmas.263824

Alnjadat, R., Hmaidi, M. M., Samha, T. E., Kilani, M. M., \& Hasswan, A. M. (2019). Gender variations in social media usage and academic performance among the students of University of Sharjah. Journal of Taibah University Medical Sciences, 14(4), 390-394. https:// doi.org/10.1016/j.jtumed.2019.05.002

Bajpai, P. (2018). Analyzing Effect of Social Media on Academic Performance of University Graduates. In Proceedings of the 2018 The 3rd International Conference on Information and Education Innovations (pp. 40-44).

Bandura, A. (1977). Self-efficacy: toward a unifying theory of behavioral change. Psychological review, 84(2), 191.

Bernama. (2019). Malaysia Ranks Top 5 Globally in Mobile Social Media Penetration, Highest in Region. News Straits Times. Retrieved July 13, 2019, from https://www.nst.com.my/lifestyle/bots/2019/01/456119/malaysia-ranks-top5-globally-mobile-social-media-pen etration-highest

Boateng R., \& Amankwaa, A. (2016). The impact of social media on students' academic life in higher education. Glob J Hum Soc Sci: G Linguistics \& Education 2016; 16(4).

Brailovskaia, J., Schillack, H., \& Margraf, J. (2020). Tell me why are you using social media (SM)! Relationship between reasons for use of SM, SM flow, daily stress, depression, anxiety, and addictive SM use-An exploratory investigation of young adults in Germany. Computers in Human Behavior, 113, 106511.

Brailovskaia, J., Rohmann, E., Bierhoff, H. W., Schillack, H., \& Margraf, J. (2019). The relationship between daily stress, social support and Facebook Addiction Disorder. Psychiatry research, 276, 167-174.

Buck, R. (2019). Motivation, emotion, cognition, and communication: Definitions and notes toward a grand theory. Advances in Motivation Science (Vol. 6, pp. 27-69). Elsevier.

Burke, M., Kraut, R., \& Marlow, C. (2011). Social capital on Facebook: differentiating uses and users. In: Paper Presented at the Proceedings of the SIGCHI Conference on Human Factors in Computing Systems. Vancouver, BC (2011). http://doi.org/10.1145/1978942.1979023

Chua, Y. P. (2014). Research Method [Kaedah Penyelidikan]. Buku 1; Edisi Kedua [Book 1; Second Edition]. McGraw Hill Malaysia Sdn. Bhd.

Curtis, B. L., Ashford, R. D., Magnuson, K. I., \& Ryan-Pettes, S. R. (2019). Comparison of smartphone ownership, social media use, and willingness to use digital interventions between generation $\mathrm{z}$ and millennials in the treatment of substance use: Cross-sectional questionnaire study. Journal of medical Internet research, 21(4), e13050. 
Dahlstrom, E., de Boor, T., Grunwald, P., \& Vockley, M. (2011). ECAR: National study of undergraduate students and information technology. http://net.educause.edu/ ir/library/pdf/ers1103/ers1103w.pdf

Daniel, J. (2020). Education and the COVID-19 pandemic. Prospects, 49(1), 91-96.

Duggan, M., Ellison, N. B., Lampe, C., Lenhart A., \& Madden M. (2015). Social media update. http://www.pewinternet.org/files/2015/01/PI_SocialMediaUpdate201 44.pdf.

Filimon, N., Girona, U. De, \& Kiygi-calli, M. (2017). Social Media and Higher Education An International Perspective. 10(1), 181-191. https://doi.org/10.14254/2071789X.2017/10-1/13

Gazi, M. A., \& Çetin, M. (2017). The research of the level of social media addiction of university students. International Journal of Social Sciences and Education Research, 3(2), 549-559.

Ghazali, S., \& Ghani, N. M. (2018). Perception of Female Students towards Social MediaRelated Crimes. Pertanika Journal of Social Sciences $\mathcal{E}$ Humanities, 26(2).

Glass, A. (2007). Understanding generational differences for competitive success. Industrial and commercial training.

González-Padilla, D. A., \& Tortolero-Blanco, L. (2020). Social media influence in the COVID-19 pandemic. International braz j urol, 46, 120-124.

Grau, S., Kleiser, S., \& Bright, L. (2019). Exploring social media addiction among student Millennials. Qualitative Market Research: An International Journal.

Giunchiglia, F., Zeni, M., Gobbi, E., Bignotti, E., \& Bison, I. (2018). Mobile social media usage and academic performance. Computers in Human Behavior, 82, 177-185.

Hawi, N. S., \& Samaha, M. (2017). The relations among social media addiction, selfesteem, and life satisfaction in university students. Social Science Computer Review, 35(5), 576-586.

Hawi, N., \& Samaha, M. (2019). Identifying commonalities and differences in personality characteristics of Internet and social media addiction profiles: traits, self-esteem, and self-construal. Behaviour E Information Technology, 38(2), 110-119.

Head, A. (2013). Learning the ropes: How freshmen conduct course research once they enter college. SSRN, 2364080. http://dx.doi.org/10.2139/ssrn.2364080

Jaleniauskiene, E., \& Juceviciene, P. (2015). Reconsidering university educational environment for the learners of generation Z. Social Sciences, 88(2), 38-53.

Junco, R., \& Cotten, S. R. (2012). No A 4 U: The relationship between multitasking and academic performance. Computers $\mathcal{E}$ Education, 59(2), 505-514.

Kashif, M., \& Aziz-Ur-Rehman, M. K. J. (2020). Social media addiction due to coronavirus. International Journal of Medical Science in Clinical Research and Review, 3(04), 331-336.

Kim, K. S., Sin, S. C. J., \& Tsai, T. I. (2014). Individual differences in social media use for information seeking. The journal of academic librarianship, 40(2), 171-178.

Kuss, D., M. Griffiths, L. Karila, \& J. Billieux. (2014). “Internet Addiction: A Systematic Review of Epidemiological Research for the Last Decade." Current Pharmaceutical Design, 20(25), 4026-4052.

Lepp, A., Barkley, J. E., \& Karpinski, A. C. (2015). The relationship between cell phone use and academic performance in a sample of US college students. Sage Open, 5(1), 2158244015573169.

MacKenzie, J., \& McGuire, R. (2016). The First Generation of the Twenty-First Century. http://magid.com/sites/default/files/pdf/MagidPluralistGenerationWhitepap er.pdf

Merchant, R. M., \& Lurie, N. (2020). Social media and emergency preparedness in response to novel coronavirus. Jama, 323(20), 2011-2012.

Ministry of Health. (2021). Situasi Terkini Covid-19 [Current Situation of Covid-19]. 
Okyeadie, M. S., \& Nizam, D. (2016). The impact of social media on students' academic. Int J Educ Learn Train (IJELT), 1(1): 14e21.

Pa, W. A. M. W., Salamuddin, N., Zin, N. M., \& Lian, D. K. C. (2020). Sports Massage Therapy Towards Pre-Competition Anxiety Among Malaysian High Performance Tennis Players. In Proceedings of the 1st Progress in Social Science, Humanities and Education Research Symposium (PSSHERS 2019), 200824.

Pato, A. S., Isıdori, E., Calderón, A., \& Brunton, J. (2017). An innovative European sports tutorship model of the dual career of student-athletes. UCAM.

Paul, J. A., Baker, H. M., \& Cochran, J. D. (2012). Effect of online social networking on student academic performance. Computers in Human Behavior, 28(6), 2117-2127.

Perrin, A. (2015). Social media usage. Pew research center, 125, 52-68.

Ransome, W., \& Sampford, C. (2016). Ethics and socially responsible investment: A philosophical approach. Routledge.

Ryba, T. V., Stambulova, N. B., Ronkainen, N. J., Bundgaard, J., \& Selänne, H. (2015). Dual career pathways of transnational athletes. Psychology of Sport and Exercise, 21, 125-134.

Salleh, M. S. M., Mahbob, N. N., \& Baharudin, N. S. (2017). Overview of "Generation Z" Behavioural Characteristic and its Effect Towards Hostel Facility. International Journal of Real Estate Studies, 11(2), 59-67.

Samaha, M., \& Hawi, N. S. (2016). Relationships among smartphone addiction, stress, academic performance, and satisfaction with life. Computers in human behavior, 57, 321-325.

Schroer, W. J. (2016). Generations X, Y, Z and the Others. http://socialmarketing.org/archives/generations-xy-z-and-the-others/

Schulze, C., Schöler, L., \& Skiera, B. (2015). Customizing social media marketing. MIT.

Singh, A. (2014). Challenges and issues of generation Z. IOSR Journal of Business and Management, 16(7), 59-63.

Sivakumar, R. (2020). Effects of social media on academic performance of the students. The Online Journal of Distance Education and e-Learning, 8(2), 90-97.

Skiera, B., Hinz, O., \& Spann, M. (2015). Social media and academic performance: Does the intensity of Facebook activity relate to good grades?. Schmalenbach Business Review, 67(1), 54-72.

Sutherland, K. E., Davis, C., Terton, U., \& Visser, I. (2018). University student social media use and its influence on offline engagement in higher educational communities. Student Success, 9(2), 13-24.

UNESCO. (2020). UNESCO rallies international organizations, civil society and private sector partners in a broad coalition to ensure \#Learning Never Stops. 26 March 2020. https://en.unesco.org/news/unesco-rallies-international-organizationscivil-societyand-private-sector-partners-broad.

Wiedmer, T. (2015). Generations do differ: Best practices in leading traditionalists, boomers, and generations X, Y, and Z. Delta Kappa Gamma Bulletin, 82(1), 51.

Tayseer, M., Zoghieb, F., Alcheikh, I., \& Awadallah, M. N. (2014). Social network: academic and social impact on college students. In ASEE 2014 Zone I Conference (pp. 3-5).

Yahya, M. W. B. H., Rahman, T., \& Siddiq, A. A. (2021). Online Learning in the Quran Reading Class during Covid-19 Pandemic. International Journal of Learning, Teaching and Educational Research, 20(5).

Zhao, N., \& Zhou, G. (2021). COVID-19 stress and addictive social media use (SMU): Mediating role of active use and social media flow. Frontiers in Psychiatry, 12, 85. 